\title{
TEMPORALIDADES Y MEMORIAS CORPORIZADAS EN LOS RITUALES AYMARAS DEL NORTE DE CHILE
}

\author{
Embodied temporalities and memories in aymara rituals \\ in northern Chile
}

\author{
Vivian Gavilán Vega* \\ Universidad de Tarapacá \\ vtgavilanv@académicos.uta.cl
}

\author{
Patricia Vigueras Cherres ** \\ Universidad Arturo Prat \\ patriciaviguerascherres@gmail.com
}

\begin{abstract}
Resumen
A partir del trabajo etnográfico realizado a fines del siglo pasado (1980-1983 y 1998-1999) en Isluga y Cariquima, dos comunidades aymaras del altiplano de la región de Tarapacá, en este artículo sus autoras reflexionan sobre las dinámicas temporales que contiene la memoria colectiva de sus miembros. Los antecedentes acopiados respecto de la religiosidad, entendida como campo de saberes, creencias y prácticas rituales corporizadas, le permiten afirmar que existen distintas temporalidades en coexistencia, configurando una historia local (oral y escrita) reconstruida por agentes reflexivos que interpretan el pasado, situados en el presente. Para ello, utilizan registros de trabajo de campo para exponer interpretaciones que realizan mujeres y hombres sobre el devenir de sus comunidades, junto con describir los rituales más importantes como memoria corporizada, los que actualizan hechos significativos del pasado que dan sentido a la vida y son necesarios para el bienestar personal y colectivo. Visto así, sostienen que el estudio de la religiosidad no solo muestra estructuras mentales, sino también procesos temporales-corporizados en permanente contradicción y no exentos de conflictos.
\end{abstract}

Palabras clave: religiosidad, aymara, rituales, memoria, pueblos indígenas.

\begin{abstract}
Based on the ethnographic work conducted in the late 20th century (1980-1983 and 19981999) in Isluga and Cariquima, two Aymara communities in the altiplano of the Tarapacá Region, this article reflects on the temporal dynamics that their members' collective memory contains. The information gathered on their religious practice, understood as a field of knowledge, beliefs and embodied ritual practices, allows the authors to state that various

\footnotetext{
* Antropóloga, licenciada en Antropología Social, Universidad de Chile. Magíster en Antropología Social, FLACSO Quito, Ecuador. Profesora Asociada, Departamento de Antropología, Universidad de Tarapacá, Arica, Chile. https://orcid.org/0000-0002-6913-378X

** Enfermera universitaria, magister en Educación, Universidad de Tarapacá. Profesora asociada, Escuela de Enfermería, Universidad Arturo Prat, Iquique, Chile. http://orcid.org/0000-0002-5961-2015
} 
temporalities coexist, configuring a local (oral and written) history that is reconstructed by reflexive agents who interpret the past, situated in the present. To that end, they use field work records to present interpretations offered by men and women on the development of their communities. They also describe the most important rituals as embodied memory, which update significant events from the past that give meaning to life and are necessary for personal and collective wellbeing. From this perspective, the article sustains that the study of religious practice does not only showcase mental structures, but also reveals temporalembodied processes that are in constant contradiction and are not free of conflict.

Keywords: Religiosity, Aymara, rituals, memory, indigenous peoples.

\section{Introducción. Los rituales y sus temporalidades}

Los rituales que realizan los miembros de las comunidades aymaras que residen en el norte de Chile se entienden en el contexto de la religiosidad actual, misma que se expresa en las diferentes adscripciones eclesiásticas, o sin ella (evangélica pentecostal, católica, adventista, entre otras protestantes). Más allá del credo profesado, este trabajo se centra en estudiar las prácticas rituales como campo de producción simbólica y como sistema de saberes y creencias que explican el orden social y sus transformaciones. Se asume que estas prácticas, en tanto fenómenos culturales, son significativas para los actores que las profesan y para los analistas. Son prácticas que los aymaras interpretan de manera rutinaria en el curso de sus vidas diarias y que reclaman una interpretación por parte de investigadoras e investigadores que buscan captar las características significativas de la vida social (Thompson, 1993).

Se entiende, también, que las prácticas rituales y los sistemas sociales en los que se inscriben, forman parte de las dinámicas sociohistóricas y, en consecuencia, los procesos de colonización y neocolonización que han vivido las comunidades de Isluga y Cariquima incluyen tanto los procesos de evangelización cristiana, en lo sociocultural, como los procesos de integración a los mercados regionales, organizados en torno a relaciones capitalistas de producción, en lo socioeconómico. Desde esta perspectiva, el Estado chileno ha cumplido un rol relevante en la consolidación del cristianismo como tradición cultural de Occidente, y, en los procesos de integración a la sociedad nacional (Gundermann y González, 2008).

Los historiadores de la primera fase de la colonización española nos han informado sobre el rol de la Iglesia católica en la imposición de la doctrina cristiana y en la negación de saberes y creencias propias de los pueblos originarios al sur de los Andes. La persecución que realizaron contra los rituales y la religiosidad se iniciaron de manera sistemática en el siglo XVI a través de métodos inhumanos. De un período denominado como extirpación de idolatrías (De Arriaga, [1920] 2002), se transitó a formas menos represivas en el siglo XX, aunque igualmente excluyentes. La violencia física y simbólica ejercida en las comunidades indígenas redundaron en experiencias de opresión, lo cual se ha manifestado en miedo, vergüenza y ocultamiento de prácticas rituales que llevaron a las familias a desplegarlas en la intimidad de sus hogares y en celebraciones colectivas semisecretas, al menos para los no 
indígenas. ${ }^{1}$ Con ello no se intenta decir que su religiosidad no se inscriba en la cultura cristiana, sino que han elaborado formas particulares de comprenderla y practicar su doctrina (Gavilán, 2013).

Son escasos los estudios etnográficos sobre los aymaras de esta región que se enfoquen en estas particularidades, en especial en las prácticas rituales y sus temporalidades. Comprender el sentido que tiene para quienes las realizan puede contribuir a conocer sus interpretaciones sobre el espacio-tiempo. Asimismo, permitiría un acercamiento a las experiencias de los aymaras y a sus reflexiones sobre el devenir de la religiosidad; en este contexto es posible examinar el tránsito que realizaron muchas familias al dejar la Iglesia católica para adscribirse a las iglesias protestantes durante la segunda mitad del siglo XX, así como la salida de la comunidad evangélica pentecostal para tomar distancia de la institucionalidad eclesiástica.

Los trabajos que se ocuparon de la expansión de la iglesia evangélica pentecostal, primero en la comunidad de Cariquima y luego en la comunidad de Isluga, tendieron a explicarla como rupturas culturales; es decir, plantearon que el pentecostalismo contribuía al proceso de desintegración social y a negar tradiciones milenarias (Guerrero, 1990, 1994, 1995; Kessel, 1992a, 1992b, 1992c; Tudela, 1992). Una visión similar la entrega Rivera, (2015) para el sur de Perú, pues sugiere que la adopción de credos religiosos no católicos implicó superponer la identidad religiosa a la identidad cultural. Sostiene esta idea en que las personas conversas abandonarían las prácticas propias de las comunidades andinas, tales como el culto a la Pachamama, las fiestas patronales y a los antepasados, entre otras; y en su reemplazo instalarían su preocupación por salvar sus almas. Al establecer una dicotomía entre identidad religiosa e identidad cultural, deja al campo de la religiosidad fuera de su contexto cultural del cual forma parte. Para el caso del catolicismo aplica la idea de sincretismo, es decir, que las particularidades de este y su larga historia en las comunidades conduciría a fortalecer la identidad cultural. Estas afirmaciones solo se sostienen en una noción abstracta de lo cultural que fija sus contenidos a esencias; la calificación que realizan los conversos, al señalar como paganas las prácticas rituales ofrendadas a entidades no católicas y ligadas al folklore a determinadas participaciones en ellas no consideran las dinámicas de cambios que experimentan las tradiciones. Pero lo más problemático es que sitúan al catolicismo como fuente de fortalecimiento de identidades colectivas. En otras palabras, el razonamiento que postula que lo católico fortalece la identidad cultural y lo no católico la desvanece, resulta incomprensible. Evidentemente, el autor entrega valiosos antecedentes empíricos para mostrar cambios en los procesos de conversión; no obstante, situarlos en la dicotomía identidad/no identidad no es adecuado, ya que saberes, creencias y experiencias operan de manera simultánea en la vida de las personas formadas culturalmente en sus grupos locales.

Andrade (2010) nos ofrece un panorama explicativo diferente para comprender las prácticas de los grupos definidos según su adscripción religiosa en el caso de Ecuador. Desde una noción de cultura interpretativista, aborda las complejas dinámicas históricas en las que se han visto envueltas las familias católicas y protestantes indígenas de la sierra. Informa

\footnotetext{
${ }^{1}$ Durante el trabajo de campo desarrollado -en agosto de 1977 y en el verano de 1980- pude constatar ceremonias en las que no permitían el ingreso de afuerinos. Entre ellas, los convites de noche en los cerros o en vertientes y en los sacrificios de animales. Al mismo tiempo, las conversaciones sobre el culto a las divinidades se establecían con mucho temor y se hablaba refiriéndose a otras personas y/o al pasado como tiempo de indios. Ser indio implicaba seguir la costumbre, y esta refería a prácticas de las generaciones no civilizadas o chullpas.
} 
cómo los protestantes han evolucionado según los contextos sociopolíticos de manera diferenciada, configurando un ethos, pero ello no lleva a esta autora a plantear que abandonan procesos identitarios respecto de la tradición indígena. Asimismo, un trabajo reciente sobre evangélicos aymaras en el norte chileno matiza la cuestión de la conversión religiosa en relación con tradiciones culturales indígenas. Mansilla y Muñoz (2017) afirman que estos evangélicos aymaras no niegan su cultura indígena, sino que interpretan relatos míticos y creencias para adaptarlos a las prácticas evangélicas; en este sentido resignifican prácticas arraigadas y resacralizan la naturaleza -entendida ahora como obra de Dios. Estos autores sugieren que, a diferencia de las primeras generaciones de evangélicos pentecostales, las actuales no ven las prácticas rituales como espacios idolátricos sino como espacios de interconexión con lo divino. También, que existirían diferencias de género a la hora de valorar y evaluar las prácticas y ritos aymaras. Por un lado, las mujeres tenderían a ser más enfáticas a la hora de rechazar las costumbres y tradiciones andinas, pues las celebraciones conducían a un alto consumo de alcohol por parte de los hombres y a una mayor violencia intrafamiliar. Agregan que en estos casos ser evangélico no implica dejar de ser aymara, por lo tanto se sienten identificados con la cultura de sus ancestros (Mansilla y Muñoz, 2017). Guevara (2009) sigue esta postura para el caso del pueblo mapuche en el sur de Chile. Afirma que la identidad mapuche contemporánea parece construirse más en procesos de interacciones y relaciones de alteridad con las "otras" identidades históricas, dejando atrás posturas esencialistas que en el ámbito de la religiosidad descartan a ciertas continuidades y, al mismo tiempo, invisibilizan reinvenciones que no por ser tales dejan de pertenecer a la tradición mapuche, o, como ella lo expresa: configuran otras maneras de "ser mapuche" y de la "mapuchidad".

Sin duda, la cuestión de la conversión eclesiástica en las comunidades estudiadas y sus efectos en las dinámicas culturales requiere de mayores y mejores investigaciones. Pero se debe tener en consideración las capacidades interpretativas de las personas para resignificar el Evangelio a partir de los sistemas religiosos propios de los grupos indígenas. Wright (2015) informa cómo entre los Takshek Qom de Formosa, Argentina, el culto pentecostal (cantos, mensajes, sanación, testimonios) se desarrolla siguiendo una ritualidad claramente shamánica expresada en un lenguaje cristiano. En este sentido, la pertenencia al Evangelio no sería una experiencia clara y distinta para los Qom, ya que presenta desafíos y contradicciones culturales que los sitúan en una tensión irresuelta entre la tradición y la modernidad. Afirma que su adscripción a esta iglesia es una nueva condición ontológica que, anclada en el devenir histórico Qom, expresa la persistencia, pero también la reelaboración de un modo de relacionarse con la dimensión numinosa y de entender el poder en sus múltiples facetas.

Los procesos de secularización ocurridos en la sociedad occidental no han sido homogéneos en América Latina y han procedido de un modo diferente en las comunidades indígenas. Nos parece que el análisis sociocultural requiere del estudio del cristianismo regional como sistema cultural occidental impuesto por las sociedades nacionales. Es decir, la evangelización cristiana, en todas sus modalidades, ha implicado prácticas de dominación que han subalternizado tradiciones de pensamiento de larga duración como el culto a la Pachamama, Inti, Malkus y T'allas; y han ejercido opresión en la medida en que las prácticas rituales se han realizado de manera oculta y/o con vergüenza de un pasado indio estigmatizado al que hay que dejar atrás para formar parte de la sociedad contemporánea. 
Desde este punto de vista, la persistencia de las ofrendas a las divinidades y del culto a los antepasados se puede entender como una batalla por la memoria colectiva que sustancia procesos identitarios (Carrasco y Gavilán, 2009). Esta hipótesis nos lleva a proponer que tanto la comprensión de la religiosidad de los miembros de estas comunidades como las prácticas rituales, respaldadas por un sistema de saberes y creencias, implican considerar el estudio de la historia local corporizada, memoria colectiva que proporciona las bases para su producción. De aquí que, a partir de nuestra experiencia etnográfica, se propongan interpretaciones de las narrativas del pasado y descripciones de rituales asociados al bienestar de las personas y sus grupos sociales, como eje del culto a los antepasados para vivir el presente. Como resultado de esto es posible disponer de un conjunto de saberes, creencias y prácticas corporales organizados en procesos temporales y no únicamente en esquemas mentales (Rappaport, 2002). Y, en tanto historia incorporada, abre la investigación a la cuestión de lo corporal y de la noción de persona desde una visión que trasciende las nociones etnocéntricas de la sociedad occidental moderna (Comaroff y Comaroff, 2001; Cuadro, 2008; Marcos, 1995; Sánchez 2015).

Estas ideas contribuyen a confirmar la tesis de la heterogeneidad social y cultural de las naciones no-orgánicas, planteada por Cornejo Polar (2003). Este autor argumenta que las temporalidades presentes en las narrativas del pasado en Perú implican modos particulares de concebirlas y vivirlas. En este marco conceptual, el pasado reconstruido por mujeres y hombres aymaras produciría textos heterogéneos que reproducen la condición fragmentada de la sociedad y de la cultura en la que se inscriben. Se trataría de narrativas en las que coexisten temporalidades diferenciadas y en conflicto, y memorias heterogéneas corporizadas. Estas diferencias no pueden analizarse de manera dicotómica (occidental/no occidental). Tratándose de sociedades y culturas heterogéneas se deberían estudiar con categorías de análisis que faciliten la recuperación de las contradicciones y conflictos que acarrea la coexistencia de distintos tiempos y diferentes espacios, producto de la evangelización cristiana forzada. Esta perspectiva nos recuerda lo señalado por J. L. Comaroff y J. Comaroff (2001) respecto de la importancia de la historia en la producción cultural de la modernidad y sus antinomias.

Esto es relevante hoy dados los procesos étnicos y de transformaciones socioeconómicas y sociopolíticas vinculadas a las dinámicas de urbanización, desagrarización y descampesinización (Carrasco y González, 2014; Gundermann y González, 2008), ya que arremeten incidiendo en un distanciamiento respecto de la ritualidad agroganadera. No obstante, ocupan un rol clave en la lucha por el reconocimiento de los pueblos originarios por parte del Estado y de la sociedad nacional para afirmar alteridades.

Estas hipótesis se sostienen en dos conjuntos de datos. Por un lado, en narrativas orales e interpretaciones de la Biblia como fuente histórica que dan cuenta del ser indígena en el presente en un mundo cristianamente compartido; por el otro, en registros de prácticas rituales que propician el bienestar de las/os comuneras/os. En ambos contextos, se observa la lucha de discursos y praxis que, a pesar de la extirpación de idolatrías, logran recuperar una historia local que les pertenece como población indígena y los provee de razones para afirmar procesos de identidad/alteridad. 


\section{La memoria colectiva. Tiempos cíclicos-lineales-cíclicos}

Price (1983) fue uno de los autores que problematizaron las formas particulares de reconstrucción del pasado en Occidente. Planteó la necesidad de revisar la universalización de esta historia y abrir la investigación a otros tipos de representaciones del pasado. Su estudio de los saramanka, etnia perteneciente a la actual República de Surinam, lo llevó a afirmar que estos indígenas seleccionan elementos, actitudes y eventos para conformar el pasado, y es de este modo que se transforma en pasado significativo, es decir, en historia. Así, propone que existiría una conceptualización y un manejo de la memoria que generan un conjunto de ideas fuerzas que relacionan el pasado directamente con la identidad, la organización social y política, las relaciones intra y extragrupales, y que además proveen un modelo moral. Siguiendo estos postulados, Rappaport (2002) sostiene que la historicidad de los nasa del sur colombiano se plantea como un proceso continuo de interpretación por medio del cual las narraciones son constituidas y reconstituidas para dar sentido al presente y proyección al futuro. Expone que la clasificación que la sociedad occidental realiza entre mito e historia se basa en que esta última organiza los hechos cronológicamente; en contraste, los mitos se estructuran en textos atemporales. Esta distinción se fundamentaba en la idea de que las sociedades no occidentales no pensaban en términos históricos, sino que integraban la memoria del pasado dentro de un esquema mítico que reflejaba estructuras mentales y no procesos temporales. En contra de esta tesis, Rappaport indica que las maneras indígenas de representar los procesos temporales no son menos históricas que las narraciones escritas de la historia académica, a pesar de que no se sometan a los mismos cánones. Al separarlas de lo que consideramos historia, por asumir que no se ajustan a criterios preconcebidos, no estamos explicando esas historias sino tan solo clasificándolas.

Rappaport sugiere que los pueblos indígenas en América Latina yuxtaponen diferentes marcos temporales omitiendo, de manera intencional, la explicación causal y se abstienen de narrar eventos de forma lineal o los localizan fuera del tiempo cronológico. De aquí la importancia que tienen las estructuras temporales ritualizadas en actividades diarias como trabajar, caminar, dormir, etc. La forma y contenido de los relatos estarían determinados tanto por la memoria de interpretaciones pasadas como por las exigencias del momento. Argumenta que si el conocimiento histórico está ligado al presente a través de esta manifestación no lineal en el espacio y en el ritual, se debe a que tiene aplicaciones prácticas. El conocimiento del pasado sería un componente fundamental en las disputas por la tierra, los acuerdos políticos y las discusiones sobre herencias; es decir, influye en las formas de interpretar el presente (Rappaport, 2002). La autora formula la tesis de que el estudio de la concepción indígena de la historia -entendida como un sistema simbólico que existe al interior de la comunidad y como formas particulares de interpretar la inserción de las colectividades indígenas en la sociedad nacional- ofrecería un campo explicativo de las necesidades ideológicas a las cuales estas comunidades se enfrentan y que son a la vez internas y externas.

Entre los aymaras del norte chileno no habría una sola interpretación del pasado. Como señalamos antes, los procesos de escolarización, servicio militar, las iglesias, los medios de comunicación y las políticas redistributivas destinadas a los pueblos originarios para administrar las diferencias étnicas y culturales explican la heterogeneidad sociocultural y socioeconómica de la colectividad que se adscribe hoy al pueblo aymara. Desde el punto de vista cultural y lingüístico, esto se expresa en diferencias generacionales. La lengua aymara como medio de comunicación cotidiano es utilizada por un grupo pequeño de 
población, especialmente por personas mayores. En tanto que los y las jóvenes solo entienden, mas no hablan. Los primeros narran el pasado a través de relatos orales transmitidos por sus abuelas y abuelos, documentación referida a herencias o pleitos, mitos de origen, cuentos, rituales, composiciones musicales y cantos, y también mediante sus prácticas textiles (Gavilán, Álvarez y Cisternas, 2016). Estos formatos combinan la oralidad, la documentación escrita y la producción textil (Gavilán, Álvarez y Cisternas, 2016; Urton, 2002) para interpretar la historia local, la que se estructura en torno a temporalidades cíclicas, sin dejar el tiempo lineal. En contraste, las generaciones letradas buscan trascender la historia local recurriendo a otros relatos para interpretar al conjunto de la sociedad indígena: la historia contada por la academia y la relatada por sus antepasados, cuyas narrativas tienden a marcar el tiempo lineal. En este segmento se observa que hasta fines del siglo pasado, los estudiantes aymaras de enseñanza secundaria y terciaria se aproximaron a la memoria colectiva a través de "los cuentos de abuelos", expresados en formato de leyendas o historias del pasado indio que reflejaban la ignorancia de la historia académica. En tanto que en las dos primeras décadas del siglo XXI, en un conexto de políticas para el reconocimiento estatal de los pueblos originarios en Chile, los jóvenes tienden a afirmar identidades étnicas valorando el pasado a través de interpretaciones históricas basadas principalmente en temporalidades lineales y, al mismo tiempo, recuperan ritualidades y las resignifican en los espacios urbanos. A pesar de estas distinciones generacionales no es posible hablar de una memoria oral y de otra memoria escrita como dos ámbitos opuestos, sino que ambas son recursos para elaborar una historia propia. Siguiendo a Cornejo Polar (2003), es posible establecer que lo que especifica a esta historia es la articulación del tiempo lineal con el tiempo cíclico y la no articulación también; vale decir, es la coexistencia de diferentes temporalidades en un mismo discurso (de manera contradictoria o no, pero en tensión) que caracteriza al relato histórico y otorga sentido a los rituales.

\section{La Biblia y los registros de la historia local}

La expansión de la Iglesia evangélica en Cariquima e Isluga durante la década de 1980 llevó a las personas de estas localidades a dar más importancia a la Biblia como referente histórico de la palabra de Dios, concebido este como divinidad que cuida y protege al conjunto de la humanidad en el mundo. Visto así, consideraban que el libro debía incluir el pasado relatado por abuelas y abuelos. Una mujer de Cariquima, que llevaba varios años como miembro de la Iglesia evangélica, se preguntaba en qué parte del Génesis aparecía la historia colectiva que aprendió de sus antepasados. Una mañana tranquila me preguntó: “¿Puedes ayudarme a buscar tiempos chipaya? Esa gente se salvó por esconderse en el agua, sabía vivir con la luna. Ese tiempo dicen que no sabía salir el sol... ¿ese tiene que salir aquí en Génesis?” (T. Ch. Cariquima, conversación personal, 1983).

Asimismo, un comunero de Isluga, católico, comentó sobre un pequeño libro de catecismo católico. Se acercó para compartir sus observaciones sobre el texto, las que sintetizó en dos equivocaciones que habían incurrido sus autores: a) no incluyeron a llamas y alpacas en el pesebre del nacimiento de Jesús; y, b) el texto nombraba solo a los hombres y no a las mujeres. Por ello, agregó a ambos animales y puso la palabra mujeres en la descripción escrita. 
Por otra parte, una amiga de la localidad de Central Citani, Isluga, quien comenzaba a incursionar en la Iglesia evangélica pentecostal, me informaba sobre la importancia de la biblia y de las enseñanzas del pastor para adoptar formas de vida acorde con la palabra de Dios. Comentó:

(...) ahora hay que estudiar la Biblia, ahí todo habla, dicen que poco a poco aprenderemos. Yo sé leer correcto, yo me he preocupado de leer, todo letra (sic) sé alzar, cualquier papel sé alzar, así el pastor también enseña que no se puede adorar, amar santo (sic) porque ese es ídolo, dice, el Señor en los cielos, no debe haber ninguna imagen en esta tierra, no se baila, no se toma, ese es el demonio, dice. Para matar a Jesús pusieron a esa gente, el enemigo, el demonio puso esa gente para matar al Jesús, dijo, con ese quedó otra gente, unas personas que se reían no más, que se contentaron cuando lo sacrificaron en el (sic) cruz, al tercer día resucitó. Cuando el Jesús no existía, gente estaban todos convertidos en animales, cóndor, lagartos, zorros, cualquier animal. Tantas señoritas dice que se habían enamorado, de por ahí, Jesús había encontrado esa Virgen María y de por ahí los enemigos le habían encarcelado, los lagartos estaban presos, se habían ido a los cerros para engañar a sus esposas, dijo. Después llegó la palabra del señor, el cura-el padre anda engañando, dice, debería andar enseñando la Biblia, no enseñar a tomar y a bailar. (C. C. Central Citani, Isluga, conversación personal, 1983)

Por esa misma época llegó a Isluga un cura cercano al dictador Augusto Pinochet, cuya práctica evangelizadora era bastante represiva. El día de muertos en el cementerio de la Marka o pueblo central, en el momento en que las familias iniciaban la espera de las almas en las tumbas, lo vieron llegar en un camión desde Bolivia. Fue entonces que las mujeres arrancaron a esconderse en los cerros. Solo los hombres permanecieron para escuchar al cura, quien dijo que oficiaría misa, alegando a través de un megáfono:

(...) dejen comida en las tumbas, vengan al otro día y verán que sigue intacta. ¡Las almas no comen, son espíritu! ¡Ya basta de tonterías! Cuando regresó por donde vino, las mujeres volvieron para continuar acompañando a sus deudos con cerveza, sopaipillas, velas, pan de guagua, etc. (Registro de campo, Isluga, 1 de noviembre de 1982)

Otro relato de un matrimonio de Cariquima, recogido en 1998, nos informaba: “( ...) Los cuentos de abuelos hablaban que antiguamente el zorro se convertía de noche en gente, de día en zorro, lagarto igual". Estas ideas contienen la existencia de un pasado antiguo que se nombra como tiempo de chullpas, un pasado remoto: "otro sol o nayra pacha", temporalidad en la que los animales se convertían en gente. Destacan el cóndor, el águila, el lagarto y los cerros, estos últimos como personas de gran prestigio: Mallkus y T'allas (señor/señora respetable), agentes recordados, especialmente en los rituales propiciatorios de llamas y alpacas. Grebe (1984) afirma que los rituales, de carácter familiar y secreto, incluyen en Isluga a animales sagrados que se relacionan con los antepasados, atribuyéndoseles gran antigüedad. Esta autora postula lo siguiente:

Se cree que estos animales sagrados, junto a los demás animales profanos, se han originado en el submundo de manqhapacha, la tierra de abajo. Son ocho: tite (gato montés), chullumpe (pájaro acuático), cóndor, águila, quirquincho (armadillo), aserro (serpiente), jaririnko (lagarto) y jampato (sapo). Los cinco primeros se conservan embalsamados para rituales. El proceso de embalsamamiento consiste en llenar el pellejo emplumado del pájaro o la piel del 
animal previamente disecada con lana de camélido u otro sustituto, procediéndose después a coserlo asociados a la "suerte", agricultura, agua y fertilidad de la tierra. Son los animales emblemáticos de sereno, el espíritu de la música. Se les mantiene vivos dentro de pequeñas cajas en la vivienda del pastor que los posee. (Grebe, 1984, p. 339)

De igual modo, Sánchez (2015) indica que existen suficientes evidencias para afirmar que en las comunidades andinas determinados animales pueden transitar entre el inframundo y el mundo presente:

Existen también seres capaces de forzar o trasponer con astucia las puertas del inframundo y transitar de uno a otro lado, en este sentido es generalizada la imagen del jaguar u otorongo, del zorro, tiwla o qamaqe, de la araña o pacha, y la mosca chiririnka. Algunos de estos seres transitantes, tienen incluso la apariencia de seres inofensivos como los monos y las lagartijas. Su extraordinaria movilidad y aptitud de traslado los hace apropiados para actuar como intermediarios entre los hombres y el mundo de abajo. (Sánchez, 2015, p. 70)

Veremos más adelante cómo estos animales son nombrados en los ritos propiciatorios agroganaderos y, a la vez, de qué manera están presentes en las prácticas terapeúticas de determinadas enfermedades que experimentan las personas residentes en las ciudades o en las localidades rurales.

Las narrativas registradas entrecruzan otro tiempo: el del rey Inka, como referente de un pasado que contiene un sistema normativo y valórico que orienta el presente (Gavilán, 2005; Gavilán y Carrasco, 2009). Esta temporalidad se relaciona con la vida contemporánea.

(...) claro Inka son esos, pues, antes andaban en sus cerros. Ese Wanapa ha venido de allá, de Bolivia ha venido, dice, pues. Por eso dice que estaba enamorado de los cerros de Sabaya de Kawarraya, tiene pareja, tiene Tata Sabaya ese, pertenece a Bolivia. Antiguamente dicen que era como un humano. Por ejemplo, mi cerro se llama Wanapa y su pareja se llama Tata Sabaya, ese era su novio. Le echaron con sertenejo al Sajama. Después, el Sabaya se enamoró, después Wanapa se arrancó, dice que estaba siguiendo, de ahí hondeó. Wanapa le hondeó. Esos son los hijos de Wanapa. Con dos guaguas ha venido Wanapa, Wanapa chico, el otro está allá al otro lado donde esta pina, pues, con esos dos hijos. Wanapa es muy jodí'o, por eso se arrancó pu, y se fue a la pampa. (F. M., Ancuaque, 1997, entrevista).

En otros relatos emerge el Inka como referente histórico del imperio y, al mismo tiempo, como propiciador del ganado y de la gente. Un respetado comunero de Cariquima, que salió en búsqueda de trabajo y otras formas de vida a los centros urbanos en la década de 1960, relató en 1985:

Los abuelos siempre hablaron de Inka-Mallku, Inka-Talla, el Rey Inka. El inka fueron los primeros hombres que vivieron en el sector sur del Perú. Y de ahí provino ya esa gente con todas sus creencias del Inka. Así que el Inka es el que respetaba todas esas creencias: wilanchas, adoraba al cerro, en fin; de ahí provino eso. Eso hablaron los abuelos... así yo desperté, así nací... así nací, pu, con esa historia de que el Inka formó esas costumbres.

(...) Lo que sí que es algo latente, los afectos a los Mallkus, que le decimos: amar a las tierras, brindar un sahumerio a los lugares donde proporciona beneficio. Entonces, en ese aspecto, los abuelos cuentan que el Rey Inka había establecido esas costumbres, entonces por eso es que todavía se respetan esa parte. Volvería a decir, el floreo sobre todo, eso se ha venido conservando del tiempo incaico. Después, los cantos del floreo, los tejidos, las trenzas de sogas, el poncho -bueno que últimamente se ha estado un poco perdiendo, pero todavía se conserva. 
Todo el sistema, el manejo de textilería, ha sido procedente inkaico; incluso está latente, pero en cuanto a relación social, casi se ha ido modernizando ese sector. (E. Ch., Cariquima, entrevista).

Un abuelo, fabriquero de una iglesia en Cariquima, compartió en su castellano aymarizado sus ideas acerca de las diferencias entre los santos patronos y los Mallkus, y sus percepciones sobre las diferencias entre los credos religiosos. Esta es su reflexión en torno al contexto en el que se insertaban las familias en $1999^{2}$ :

Wilancha, ese de Inka. La mesa cualquier compadre, comadre, esa es otra cosa. Esa es otra cosa, Mallku todo, eso no, pu, fiesta no más, pu. Antiguo aymara es, pues, Kollanta, dice, ahora no, pu, ahora indio nomás. Yo sé escuchar al tata marusa mama, ese tiempo sabe antigua, ese tiempo habla, sabe. Ahora Biblia, claro, falsificado es Biblia, el hermano que habla, dos mil años... dijo, ¿no? El Ejército de Salvación dice 2.500 años más allá todavía, vamos a ver, 3.000, tiene que cumplir tres personas, el padre... dos mil va a ver, mejor año va a pasar, por eso falsificado la Biblia. No ahora, hambruna lo que pasó, ese tiempo, porque ahora 2000 no va a ver na' pal año, no va a ser buen año, este año 99 ya casi está, el 2000 ya. Ese no, pu, evangélico dice el diablo, puro malo, diablo, no, no es diablo, porque diablo es inocente, porque diablo es otra forma, es otro. Porque el llamo no se formó del Dios ni padre, es Inka, como nació el piedra, en cerro, el Inka hace nacimiento, nació del llamo, eso, claro, ahí el señor le bendición [...] todo levantó esta tierra, por eso tres mil años tiene que cumplir, ahí vamos a ver necesitado los vicios... por eso hay que florear llamito, porque el Dios que marcan por eso que florean por el Pachamama, el Inka Mallku, Inka T'allla está viendo [...], el Inka hace el llamo, no la gente, el dios, no, eso es de Inka. Por eso hay que dar bendición, esta tierra todo comimos, todas las plantas, quinuas, papas, arroz todo comimos [...], no cumple, después pasa cualquiera cosa, por eso no llueve, ahora la Biblia el señor no... el volcán el que manda, volcán el señor dice [...], cuando no amamos pasa nomás, le encomienda cuide ganado, por eso challar, eso decimos, esos otros dicen diablo, aviador, dicen diablo, diablo, diablo [...] los evangélicos dicen no hay que bailar, no sirve hacer floreo, el santo hay que quebrar todo, ¡cómo burro vamos a vivir!, hijo se nació del piedra, por eso tenía el Inka, por el español lo mataron esos, porque saben de esos tiene oro, metales tiene, de ahí lo mataron, el cuerpo, de ahí el Perú... ¿ahora está manteniendo el Perú? [...] El Inka, eso sabemos, es como un Dios, que vale como un Dios padre, el Inka, por eso estamos viviendo pobres acá, así no antes, seríamos ricos mismo, mucha plata, el señor se enoja, el Inka se enoja, no. Como Dios poderoso es el Inka, poderoso... (F. M., Cariquima, entrevista).

Es posible advertir que la Biblia, como referente histórico y mítico, es interpretada de diferentes formas buscando articular la historia local con la historia cristiana, no como dos cosas separadas, sino como un conjunto de hechos significativos del pasado; no obstante, se disputa la validez de los saberes ancestrales. Esto ha sido registrado también en zonas rurales de la sierra ecuatoriana. Andrade (2004) afirma que la Iglesia evangélica en expansión en la sierra ecuatoriana, liderada por pastores quichuas, realizan una reinterpretación de la Biblia a partir de sus propias experiencias y de las de sus antepasados en relación con seres tutelares. Por tanto, hacen una interpretación propia de la Biblia, dando cabida a sus propios saberes.

En esta dinámica se ve que el presente, representado en los bienes necesarios de las personas (alimentación, mantención), se articula con esos saberes y creencias. De aquí la temporalidad cíclica, pues el pasado emerge en el corpus de normas y valores legadas de los

\footnotetext{
2 Transcribimos el texto de manera fiel a la expresión verbal del entrevistado para exponer su interpretación de los conflictos que generaron en esta época las diferentes incursiones eclesiásticas.
} 
achachilas o abuelos, en expresiones como recordar, respetar. Al mismo tiempo, las personas con mayor escolaridad y que combinaban la residencia rural con la urbana, católicos o evangélicos, tendieron a pensar estos argumentos como leyendas del pasado indio, incluso los caracterizaron como propios de un tiempo de ignorancia que debe superarse, marcando un tiempo lineal y acercándose a una visión moderna de la religión.

El pensamiento de la gente en este momento es, bueno, vivir así en forma moderna. Y eso ya, ya no se puede, es como ir retrocediendo si empezamos a vivir con las mismas costumbres antiguas que [...], bueno, ahora la gente considera como retroceder como para ese tiempo, y eso es lo que no está tan correcto, diría yo. El pueblo aymara, claro, es un origen, una raíz que ha venido gestándose desde el tiempo del Imperio incaico. De todos esos alrededores donde vive la gente aymara actualmente, todos son descendientes incaicos. Después de los incas llegaron españoles ya, y se territoriaron con el nombre peruano, y bueno, siguieron siendo peruanos; $y$ luego ya por guerras y qué se yo, también entró la legislación chilena y actualmente la gente aymara en el sector chileno vive como chileno. Pero, en el fondo, sus costumbres, su manera de ser, su cultura, eso no lo van a cambiar nunca, van a conservarlo siempre. Eso sí en forma más ordenada, o sea que, en vez de ser casas de piedras, que antes se usaban mal talladas, ahora podrían tallarse mejor, más [...]. En cuanto a las construcciones, ya van a ser más cuadraditas, no tan deformadas, en fin, en ese aspecto. Ahora en la manera de cultivar los terrenos, ya van a ser más modernizadas ya, con canales de cemento, en fin, en esa forma ya va preparándose la gente aymara. (E. Ch., Cariquima, entrevista, 1985)

Al consultarles a algunos jóvenes que cursaban la enseñanza media sobre este aspecto, ellos decían no saber del pasado, no haber estado presente en los rituales, pero sí conocían las prácticas de sus abuelos y explicaban el entorno como paisajes y describían los volcanes como parte de la naturaleza. Al preguntar por Inti, por ejemplo, dijeron: “(...) pero nosotros no sé [...], es como lámpara. La luna igual [...], la ignorancia, anteriormente los curas creían que esos eran Dios pu, el sol para mí es algo que nos da calor, abrigo y que nos alumbra”.(Entrevista, 1998). De este modo, en las narrativas coexisten diferentes aproximaciones al tiempo-espacio según sea la generación; sin embargo, habría que considerar los deseos de las y los jóvenes en la década de 1990 por modernizarse, quienes con un mayor entendimiento de la sociedad nacional buscaron secularizar el pasado, ya sea genuinamente, ya sea como estrategia de interacción con los no indígenas. Como sea, las personas adultas razonan para entender sus vidas en el presente:

Yo entiendo así, mire, ahí está bien claro, cómo Dios creó - digamos-, Dios está en el universo, es un ser invisible, es un poder invisible ¿ah?, por ahí. Entonces, él creó la tierra, el cielo, todo, ya está, vayamos un poco de acuerdo a la historia bíblica, ¿ah? Entonces, la naturaleza funciona viva, está viva la naturaleza, ¿cierto?, todo, todo funciona vivo, no hay ni una cosa muerta en la Tierra. Entonces, así creó Dios. Entonces, en primer lugar, el respeto al Dios todopoderoso, y en segundo lugar, a la santa madre Tierra que funciona viva, que nos da vida a todo el ser humano, a toda la humanidad. Entonces, entre ese respeto, en ambas partes se complementa en uno. Bueno, ahora, en la religión dice que hay dos poderes, que el otro es el diablo, que el diablo está metido en la Tierra. Yo no creo en el diablo. Ahí yo digo, bueno, si hay diablo, habrá ya, ¡pu!, pero yo no voy a "que el diablo me está haciendo esto, que Satanás me está haciendo esto"; yo no voy a eso. Entonces, el que hace maldad, bueno, es que hace maldad por su propia cuenta [...], lo que está procedido, lo que hacen ellos ya es por su propia cuenta. Entonces, los evangélicos dicen que el diablo está metido en la Tierra, y en la Tierra hay cualquier cantidad de desorden, de peleas, de guerra, ¡qué sé yo!; porque el diablo está preparando eso para que la humanidad viva mal. Entonces, bueno, si es que hay diablo, ¡habrá diablo!, quizás dónde estará, 
habrán diablos, que haigan diablos, ¡ya! Pero yo lo respeto a la santa madre Tierra que me da de comer también, que me da de vivir, yo lo respeto. (E. Ch., Cariquima, entrevista,1990)

Este relato justifica lo antes dicho y muestra de manera más clara que Dios, como ser supremo, debe estar unido a Pachamama; sin ella no se puede explicar la vida, tampoco la historia de sus antepasados que posibilitan el bienestar de la población actual. Pachamama, esto es, Mallkus y T'allas, achachilas (abuelos), que cuidan y protegen a las nuevas generaciones. Para una mayor comprensión de las temporalidades referidas, describimos a continuación los rituales. Estos ofrecen un campo de estudio privilegiado para acercarnos a las tradiciones culturales corporizadas en quienes las practican, de modo de generar procesos de identidadalteridad.

\section{"La costumbre", rituales propiciatorios y la importancia de los uywiris}

Las personas adultas aymaras suelen ocupar la palabra "costumbre" para referirse a las prácticas rituales legadas de los antepasados y esta condición implica situarse en la intimidad de los hogares. "La costumbre" era aquel conjunto de saberes, actividades y convicciones que los achachilas (antepasados) exigían actualizar en el presente para lograr el bienestar de la comunidad. El culto a Pachamama, Mallkus y T'allas se sintetizaba en la palabra castellana "amar", término que se repetía al igual que el de "costumbre" para nombrar el apego a las prácticas rituales aprendidas de las generaciones anteriores.

En Isluga se celebraban ampliamente la fiesta del ganado, año nuevo e inicio de la siembra, y carnavales o fiesta de la gente. Mientras que en Cariquima, la celebración de la primera y la segunda fiesta, en las dos últimas décadas del siglo pasado había disminuido como efecto de las adscripciones a la iglesia evangélica pentecostal. Otra característica de estas festividades era su alcance comunal y/o familiar. Los carnavales y la fiesta patronal del pueblo central (Santo Tomás de Isluga junto a Santa Bárbara y Mamita Concepción, y San Juan de Cariquima junto a Santa Bárbara y Mama Presentación) siguen convocando al conjunto de comuneras y comuneros. Las otras se reducían a grupos locales conformados por grupos domésticos residentes en pequeños poblados que denominaban estancias.

En todos los casos se trataba de momentos de celebración y encuentro con los antepasados, con los seres tutelares, para agradecer, pedir y recordar ofrendando, bailando, bebiendo y comiendo; para entrar en comunión con ellos y recibir su bendición; es decir, para colmarlos de bienes, de salud y prosperidad. La fertilidad como eje del bienestar y en particular la protección frente a calamidades eran el centro de las peticiones. Todo ello se expresaba verbal y corporalmente al compartir ese pasado a través del acto de recordar a Mallkus-T'allas -como uywiris (quienes nos crían, tanto a las personas, al ganado, a las plantas, a la vida) - para alcanzar éxitos en la producción y reproducción mediante actos de reciprocidad.

Las tres festividades (de la agricultura, del ganado y los carnavales) muestran componentes comunes en las ceremonias. Se entienden en el calendario ritual asociado a los ciclos productivos, mismos que siguen un patrón dentro del ciclo climático (tripartito) y de los solsticios (Gavilán y Carrasco, 2009). La fiesta de la agricultura se inicia en agosto, mes de inicio del reciclaje agrícola (año nuevo para los aymaras). La fiesta del ganado es en los meses cálidos de enero y febrero, período de pariciones de llamas y alpacas. Los carnavales coinciden con la celebración cristiana de la cuarentena que impone la semana santa y con el período de inicio de las primicias agrícolas. Con ciertas variaciones, las festividades duran 
aproximadamente tres días. Se inician con la antevíspera, en la que se realiza el ritual de petición a los abuelos a media noche -de preferencia con luna llena-, momento en que se permanece hasta el amanecer y se realizan mesas rituales en la casa. Continúa con la víspera, el día principal, y la cacharpaya o despedida. El ritual principal consiste en la ofrenda de una mesa con elementos propios de este pasado (textiles, hoja de coca, inciensos, licores, grasa, animales embalsamados, flores, pastos, entre otros). Una de las partes centrales de la ceremonia es la sangre de una llama o alpaca, especialmente del corazón y de los pulmones (las entrañas), denominada wilancha, la que se oficia antes del amanecer en honor a Pachamama (Mallku-T'alla) para agradecer, pedir, recordar, compartir, en el cerro, en los corrales o en la chacra: allí donde están los Uywiris, es decir, quienes nos crían. Pueden ser Pukaras (piedras, pirkas o lomas ubicadas en los contornos de la comunidad), en la mitad de los cerros; ojos de agua o vertientes, en las orillas de la Marka o pueblo central. Se ubican en el paisaje familiar, comunal, al oriente y al occidente, a ellos se les prepara la mesa ritual y se les nombra en las ceremonias.

G. Martínez (1976) afirma que los uywiris o seres tutelares, aviadores de los grupos de parientes en Isluga, son antepasados que vivieron en otros tiempos. Uywa o uywaña, en lengua aymara, alude a crianza. Un comunero de Isluga traduce uywa como animal doméstico (García, 2005) y uywachaña, como crianza de animales. Lo interesante de estas definiciones es que nos indican cómo el sentido común aymara contemporáneo vincula los significados de crianza con animal doméstico, específicamente llamas y alpacas. En la lengua castellana alude a la acción de criar, es decir, de producir algo con afecto, referido a la relación de los recién nacidos con su madre o nodriza. Estas ideas facilitan la comprensión de la trama de los rituales, especialmente los dedicados al ganado, pues las narrativas y las ceremonias asocian a la humanidad, a las llamas y alpacas con el Inka: son crías del Inka rey. Las representaciones que se hacían en las fiestas de los uywiris, tanto de la agricultura como de la ganadería, correspondían a una pareja de comuneros vestidos a la usanza antigua. Vestían talegas con semillas, o bien, con piedras, con toda la indumentaria tradicional. En el caso de una estancia de Isluga, la comunidad amaba a Pukar Mallku Pukar T'alla, situados en una pirka (muro de baja altura) en la pampa de cultivo. En la ganadería, tanto los cerros como las vertientes son femeninas y masculinas; en otra estancia, también de Isluga, veneraban a un ojo de agua, al que invocaban como Jutur Mallku-Jutur T'alla.

Podemos ver que comúnmente los uywiris son representados como adultos y por lo general, en pareja, en edad productiva. Pueden ser matrimonio o amantes, ya que otro atributo que resalta es su sexualidad (Carrasco y Gavilán, 2014; Gavilán y Carrasco, 2009; Martínez, 1976). Son los responsables de reproducir la vida en el presente. Así como la noche es su contexto y la luz del día, el de los oficiadores del rito vinculado a Dios; la sangre y grasa para los antepasados; la chicha y licores, la hoja de coca y la comida sin sal que se les ofrece son compartidos. Como veremos en los ritos propiciatorios del ganado, sus significados y resignificados se comprenden como corporalidades compartidas con los achachilas (abuelas y abuelos). Estos antecedentes coinciden con lo expuesto por Sánchez (2015), quien postula que:

Los restos mortales de parientes pueden considerarse guardianes o protectores de sus descendientes y que se expresan como marcadores del espacio: wankas, saywas (formaciones pétreas), colinas y montañas, bajo nombres diversos: chakrayoq o korpa patjaru (espíritu al cuidado de un área de sembrío), achachila (ancestro identificado con una colina u otro promontorio, generalmente ubicado como vigilante de los linderos de una llaqta o población), apu, jirka (ancestro al que se le considera asentado en grandes montañas, generalmente nevadas, tratándose de espíritus estimados de gran poder). (2015, p. 75) 


\section{El wayño, fiesta del ganado. El relato etnográfico y la memoria de las mujeres}

Saliendo de "Todo Santo" y del día de las almas (31 octubre-02 de noviembre), las familias del altiplano ofrecen banquetes a Mallkus y T'allas para pedir por la multiplicación del ganado. Se realiza la marcación, o quilpa, y se ama a los animales en su período de apareamiento y nacimiento de nuevas crías. La fiesta completa puede repetirse o efectuarse cada tres años por los costos que implica. Los días preferidos son dos semanas antes de carnaval, en días compadre (Mallku) y comadre ( T'alla). El lugar específico de adoración a los uywiris puede variar: puede ser el cerro, la pirka o los ojos de agua. Sin embargo, la ceremonia ofrecida en el centro del corral de los animales o cancha es obligada. El centro del corral dispone de una piedra aplanada o cuadrada. Asimismo, esta puede estar ubicada en medio de la montaña. En Cariquima, por ejemplo, dicen que está justo en medio del cerro T'alla Wanapa, principal cerro uywiri de esta comunidad. Al centro de la piedra, por debajo de la misma, hay un hueco donde le entierran cuatro llamas -hechas de barro por las mujeres-floreadas: dos grandes, hembra y macho, y dos pequeñas, hembra y macho, lo que llaman Planta. Una joven nos contaba en 1982: "[...] a una piedra le aman, que sea grande, yo no sé mucho, pero le aman a eso, tienes que regalar al cerro, ese día tienen que regalar la piedra, así saben decir: ¡kuntur mallku, agil mallkuuuuu!’ (L.A., Colchane, entrevista).

Cumplimiento es la palabra usada para el ofrecimiento del banquete a los aviadores del ganado. Los componentes centrales de este banquete son la Chuwa o bebida ritual, la wilancha o sangre y la grasa.

Cada tres años hay que invitar a los cerros. Nosotros llamamos achachilas. Ponemos licor de todas clases, como 12 licores: menta, chirimoya, pisco, vino, cocoroco. Entonces, invitamos al cerro Caracarane; ese tiene de todo: leña, carbón, yareta. Para que se mantenga el ganado, para que crezca bonito el pasto, para que no coma el zorro. Ese cerro tiene muchos zorros; si invitamos algo no comen nuestros animalitos. Cuando empezamos a cruzar llamos, les damos también. Tenemos hechos unos cuadraditos para hacer pagar la tierra, en Unanitrapa (al medio del corral). Mesa se llama, se hace con banderitas, con coquita. Esa es mi costumbre antigua, ahora ya se está perdiendo. Antes lo hacían todos los años y ahora cada tres años nomás. (T. Ch., Wayatire, 1993, entrevista).

El wayño solía ser una fiesta más sofisticada que lo que es hoy. Se preparaban con varios días de anticipación los adornos de los animales, las bebidas, la comida, etc. En la antevíspera, los patrones llaman a sus achachilas o abuelos y los esperan para compartir el banquete:

Seis botellitas se ponen en la mesa: Korelimpie, mullu y sibario a un lado, kopal puro, kullu y llimpaja. Algunos de estos son de maíz y quinua, y son preparados por las mujeres. Eso se pone en antevíspera. En la víspera hay que collar con hoja de coca y kopal en una mesa ritual que consiste en un costal tejido sobre el que se dispone de estos elementos. Hay que amanecerse toda la familia, conversando en el corral con Mallku T'alla, mirando al mamakulla (llama hembra) orando y tomando. (T. M., Cariquima, 1998, entrevista)

Al amanecer se ofrece la wilancha, o sacrificio de un animal. El corazón al sol y la sangre a Pachamama. Luego se entierra. Las patas se disponen a los costados de la mesa ritual, la que además contiene un florero con los pastos que acostumbra a comer el ganado. 
Se pide por la multiplicación del ganado, que no se mueran de frío, que haya pasto, que no se enfermen, y que puedan comprar vehículos con la venta de animales. En la casa se dispone de otra mesa. En vez de un costal, ahora será un jawayu o manta con hoja de coca, azúcar, alcohol, campanillas y los animales pastoreros o awatiri rituales: un gato silvestre llamado Titi, embalsamado, animal que cuida el ganado en el campo, y un pato acuático o Chullumbi, que hace emerger el ganado desde las profundidades. Chimbas (o lanas) de colores, sombreros, adornos para hembras y machos, ango (collar de lanas), zarcillos para las hembras y banderillas para machos completan el ajuar. Aquí se hacen las veces o se challta (brindar con alcohol) y se comparte. Los cantos y los bailes empiezan con "el wayño k'allu con k'anzucindo, cadenitas y al amanecer se interpreta el tiutipilasiña y el zafanditauj", nombres que reciben las diferentes composiciones musicales que incluyen bandolas ${ }^{3} \mathrm{o}$ armónicas.

Se comienza el ritual con las delanteras en par; es decir, primero las llamas, luego las alpacas: las jóvenes y luego las crías, para finalizar con los machos. Para poner los adornos, se pasa una pasta de maíz molido por la mitad del animal en forma de cruz, se challta con alcohol, chicha y coca para dar la bienvenida, y se va a la mesa y luego se adornan. A las hembras se les pone solo en la mitad del lomo y a los machos, desde la cabeza hasta los costados. Después de florear, se deja el trabajo y todos van a la mesa para challtar y acompañar a los patrones. Llevan bandolas para cantar a las alpacas y llamas, y dar cariño. Cada animal tiene su propio canto.

El patrón se carga su jawayu (uywa q’ipe o atado de mis uywiris o criadores), que ha servido de mesa, y la mujer la suya, con adornos que sobraron, y vuelven a quemar copala (incienso). Se envían los animales al campo. Una de las personas que acompaña, dirige a los invitados que han ayudado, lo que se denomina con el término alirina o alikina. Estos traerán leña cargada con soga. Semejarán ser una tropa de animales que llega a su corral. El patrón, entonces, llegará arreando sus llamas, cantando y bailando. Afuera de la casa habrá fogata o luminaria, allí se darán tres vueltas y entrarán a poner la mesa y dar vueltas cantando y bebiendo. El patrón sale a recibirlos y empieza el baile. Luego comerán. La comida consiste en hígado picado, guatitas y bofe picado con papas y chuño y harina o sémola. Los bailes consisten en rodear la fogata. Se forma una fila de hombres y otra de mujeres. Van cantando y bailando, formando un trenzado, desafiándose con los cantos en aymara. Los hombres tocan sus bandolas y las mujeres les contestan: "Tu imilla pareces alpaca, tienes ojitos de alpaquita, puedes mirarme por favor". Así, se continúa hasta la madrugada.

En una de estas ceremonias, en la estancia de Colchane, Isluga, fuimos invitadas por un comunero, quien guio a sus parientes a la puerta de nuestra casa en la noche, en fila, cantando y bebiendo, para que asistiéramos a la celebración. Al señor que guiaba la fila, lo llamaban awatiri o pastor del rebaño. Llegamos a saludar a los "patrones" o dueños del ganado, los anfitriones, quienes se situaban frente a la mesa ritual, adentro de su casa. Nos recibieron explicando por qué estaban festejando al ganado y sus deseos por compartir con nosotros la costumbre o lo que les enseñaron los abuelos. Luego nos invitaron a salir a la fogata para integrarnos al círculo de mujeres y hombres de la familia que rodeaban el fuego. Nos dijeron que en el baile éramos todos ganados y que el awatiri nos lacearía con sogas a todas y a todos. Teníamos que actuar como llamas y alpacas, hembras y machos. Aquel hombre que no se dejaba lacear, era el líder de la manada y principal reproductor. Cuando lograron lacearnos, nos llevaron a la mesa de los patrones para vendernos. Se trató de una larga negociación entre los vendedores (los alféreces) y los compradores (el pastor que me laceó) para consensuar el

\footnotetext{
${ }^{3}$ Instrumento musical de cuerda del tamaño de un charango.
} 
precio. Los vendedores decían que el precio debía subir porque el pelo claro (representaba la calidad de la lana de alpaca), era muy cotizado en el mercado. Los compradores pedían rebaja porque debían llevar la mercadería a Argentina en avión, lo que significaba un gasto grande. Todo esto en un ambiente festivo y chistoso. Estuvimos hasta el amanecer y volvimos a la casa acompañados hasta la puerta, momento en que el awatiri nos aconsejó que descansáramos tranquilamente.

Al otro día, todo empieza igual que el día anterior, a excepción de la wilancha. Al medio día se despacha a los animales y se regresa a casa a almorzar. Se dispone una frazada al lado de la mesa, un jawayu, sobre el cual se ubica una rueda de carne asada, mote maíz, mote de habas, papas y $p$ 'ire (merengue de maíz especialmente para esta ocasión). Se sirve una cazuela y el patrón invitará entonces a la boda; esto es, el almuerzo que se dispone encima de mantas, y se preparan los alimentos sin sal para compartir y en señal de comunión con los antepasados.

Otra manifestación central de la fiesta es la música que acompaña en todo momento los días de celebración. Esta expresa los profundos sentimientos de amor por los animales. Las letras y melodías se relacionan con el manejo y cuidado que mujeres y hombres realizan como pastoreros, pero también se crea un ambiente sensual. En este ambiente festivo, la interacción entre los géneros invita a la conquista, para lo cual se compite para exhibirse como el ideal de pareja: el mejor compositor de música y letras, el mejor carneador, la mejor cocinera, la mejor pastorera, la mejor cantora, etc. Entre cantos y bailes se genera un espacio que convoca al despliegue de emociones y al deseo sexual, pues desde la salida de la celebración de Todos los Santos es un tiempo cálido y estimulante para la reproducción de animales y seres humanos. Por ello, los cantos incluyen temáticas relacionadas:

En el wayño se canta cargando éinéirkoma (hierba de los cerros) para que las llamas hembras queden preñadas. Se baila y canta al Chullumpi (pato del bofedal). Se ponen frente a frente filas de mujeres y de hombres. Se desafían, las mujeres cantan con voz muy aguda. El canto dice más o menos así: "Tú, chullumpi, estás en juré (barro negro), pero mi chullumpi está en el corriente de agua". El joven habla y la mujer contesta de inmediato. Puede ser acompañada por bandola. (C.C., Isluga, 1982, entrevista).

Uno de los cantos a la alpaca macho reza así:

Ay kani ay kani murmutan murmutan

Parisa, parisa, Q'ellevire

Taypirana parisa parisa

Chopejero Haniw Kaukistas

Jumarka

Palabras de cariño, negritos, negritos, un par gris, mayoría gris, tropa café. No es cualquier animal. De todos colores pelo. Murmunta, nombre propio del lugar donde come la alpaca. (C.C., Isluga, 1999, entrevista).

Una vez que asistimos a un wayño comunitario, en una comunidad en la que la mayoría de sus miembros habían adoptado la religión evangélica pentecostal, bailando en medio del corral en círculos, una abuela lloraba y decía muy emocionada: “¿Cómo dejamos esto?, ¿tonto estábamos?, ¿cómo olvidamos? ¡Si por ganado somos gente!”. Se pasaba del llanto a la risa, del recuerdo a los hechos actuales y a la invocación a Mallkus y T'allas, de las recriminaciones al amor profundo. Eran momentos en que la memoria se mostraba incorporada en los uywiris que se conmemoran y en los cuerpos de mujeres y hombres, 
momentos en los que el presente y el pasado se confunde, en el que llamas y alpacas y seres humanos se funden en una sola materia como hijas e hijos de antepasados comunes.

La corporalidad expresada en los rituales del mundo mesoamericano ha sido reseñada por Marcos (1995) como filosofía encarnada. Esta autora afirma que lejos del pensamiento cartesiano, los nahua conciben la corporalidad como expresión de la vida expuesta a los rumbos del cosmos: singular y móvil que incorpora en su núcleo sólidos y fluidos en permanente flujo: aires, vapores, jugos y materias, y, en este sentido, se articula con espíritus o entidades sagradas. En el caso aymara, esta dinámica se inscribe en los cuerpos, cuyo centro vital se ubica en el ánimu, sustancia que conecta a la humanidad con Pacha (universo, tiempo-espacio), y con los antepasados que se ubican en el inframundo y que nos visitan cada año en la estación cálida (noviembre-abril) (Gavilán, Vigueras, Madariaga y Parra, 2011; Gavilán y Carrasco, 2009; Sánchez, 2015).

Esta fusión entre pasado y presente, expresada en la corporalidad, se manifiesta de igual modo en los sueños como revelación de los Mallkus y T'allas (antepasados), santos y santas patrones. ${ }^{4}$ Se trata de corporalidades similares a los humanos, que están atentas al comportamiento moral de los miembros de las comunidades, vigilándolos, ya que la pérdida de memoria y la falta de reciprocidad los lleva a sancionar a la población del presente atentando en su bienestar. Esto aparece en las narrativas de las personas como castigo, impidiéndoles el éxito en el trabajo o afectando su salud o la de sus familias. Si no se realiza el wayño, por ejempo, pueden ocurrir situaciones indeseables:

Si tú no le haces wilancha, se te mueren los llamos. Todos los años el día comadre antes del 2 de febrero, antes de carnaval, el día jueves, esa es la tradición de los ganados. Es por obligación que hay que hacer eso. Si no haces, te darás cuenta que se te pierden, se te mueren, se los comen por el campo cualquier cosa, entonces, si tú haces ese cumplimiento a esos animalitos, a los llamos, a los alpaquitos, te va bien. Por ejemplo, lo que piden en la cancha es para los Mallkus, para que esa wilancha uno le da a los Mallkus pa que ellos no vengan a comer sus guaguas, a los ganados, ¿ya? (J. M., Cariquima, 1999, entrevista).

Estas entidades han sido catalogadas como demonios (primero por la iglesia católica y en las últimas décadas por la evangélica pentecostal). Dioses/diablos van siendo reinterpretados en un contexto de constantes luchas por estar en este mundo con un pasado que ha sido negado y estigmatizado, el que se compone de hechos significativos que explican lo que son: descendientes de abuelas y abuelos que les enseñaron a vivir con normas y valores que deben respetar para ser persona o Jaque. Estas normas y valores guían el presente y el futuro.

Ontológicamente tales entidades comparten corporalidades (ánimu-chima) arraigadas al territorio, entendido este como espacio tiempo, lo que se manifiesta en enfermedades actualmente presentes en las comunidades y que solo los agentes comunitarios pueden resolver, porque son los únicos que saben pedir a los uywiris (demonios) que devuelvan el ánimu que han extraído de quienes las padecen a modo de castigo o reprimenda. Esta situación puede vincularse a lo hallado por Andrade (2004) en Quito, quien comenta de seres asociados a la naturaleza en comunidades quichua, a los que se les atribuye poder para causar enfermedades; o con la idea planteada por Sánchez (2015): “Las especies y el mundo inorgánico están animados por una

\footnotetext{
${ }^{4}$ Aunque no disponemos de datos etnográficos sobre el lugar de los sueños en estas comunidades, registramos antecedentes sobre la importancia que tienen estos como justificación de las aceptaciones para asumir cargos en las fiestas de santos patronos o en carnavales, y en las prácticas de sanación de yatiris (agentes comunitarios que restablecen la salud).
} 
vitalidad común. El universo está poblado por seres poseedores de energía o kamay en distintas proporciones, los cuales establecen una relación de crianza mutua entre sí” $(2015$, p. 77).

\section{Reflexiones finales}

Hemos puesto la atención en la religiosidad aymara como campo de saberes, creencias y prácticas rituales corporizadas, que muestran concepciones del tiempo-espacio propias de comunidades descendientes de los pueblos originarios de la actual región de Tarapacá. Identificamos dos aspectos -entre otros- que nos refieren a la historia local de Isluga y Cariquima: las interpretaciones de los contenidos históricos del mundo cristiano expresados en la Biblia y el despliegue de ritos propiciatorios, especialmente el de la ganadería, para afirmar que nos hallamos frente a personas que reflexionan sobre el devenir de sus comunidades. Utilizamos registros de trabajo de campo para exponer interpretaciones que realizan mujeres y hombres acerca de las temporalidades en las que transcurre la vida.

Tanto las formas de comprensión de la historia europea como las relatadas por abuelas y abuelos aymaras se fusionan para actualizar hechos significativos del pasado que dan sentido a la vida y que son necesarios para el bienestar personal y colectivo. Asimismo, los rituales que practican, actualizan la memoria corporizada y son significados como procesos temporales. La dinámica de ambas prácticas muestra contradicciones y conflictos que, a veces, articulan la circularidad y la linealidad del tiempo.

Las ofrendas a los uywiris nos conducen a la historia local corporizada y a una forma de ser cristiano que enfatiza la temporalidad cíclica, pasado y presente. Los cuerpos que se alimentan y beben se unen en uno solo: el del mundo indígena. Ellos son continentes de hechos y valores que guían los comportamientos de la comunidad en el presente, aquellos que nos crían, cuya naturaleza es igual a la de la humanidad y a la de las llamas y alpacas. Aunque actualmente la fiesta del ganado se restringe a un grupo pequeño de familias, la fiesta de la gente o carnavales sigue siendo el tiempo-espacio en el que la comunidad se reproduce y en el que los antepasados vuelven al presente para proteger y otorgar bienestar a las nuevas generaciones.

Los miembros de las comunidades estudiadas pueden yuxtaponer tradiciones, o bien, distinguirlas y contraponerlas, produciendo sentidos según las exigencias del presente. De este modo, configuran estructuras temporales ritualizadas, sean fieles evangélicos, católicos o no tengan adscripción religiosa alguna. Los procesos temporales que muestran las narrativas y los ritos se despliegan para configurar una historia local que va produciéndose desde las condiciones de vida del presente. Sin embargo, no hay una sola interpretación del pasado. Como señalamos antes, los procesos de escolarización, las iglesias y sus agentes, los medios de comunicación, entre otros, continúan ejerciendo opresión, ya sea negando la historia local o restringiéndola al folklore. Aunque también lo han hecho los postulados occidentales, plasmados en la academia, ya que aplican la razón secular para clasificar los mitos de origen como sistemas de creencias y no como contenedores de saberes. De aquí que estar atentas y atentos a cómo el pasado interviene en el presente -y al revés- nos puede llevar a una mejor convivencia en torno a la diferencia cultural, pero sobre todo a tener conciencia de la lucha política que se libra en condiciones de desigualdad.

Si bien los antecedentes etnográficos expuestos se sitúan principalmente a fines del siglo XX, en un contexto en el que los cambios ocurridos llevaron a la mayoría de las familias a vivir en las ciudades, a practicar actividades económicas no campesinas, a adoptar nuevas 
formas de organización del trabajo y a establecer una mayor diferenciación social, la historia local aquí esbozada se manifiesta hoy en el campo de la salud. Las enfermedades que afectan a las personas y a sus grupos familiares (katjata o agarradura y rekaira) no son posibles de curar mediante los sistemas sanitarios, por lo que se ven ellas en la necesidad de acudir a agentes comunitarios, quienes ofician como sabios y expertos de la historia local, lo que les sirve como respaldo para devolver la salud de estos enfermos. Tanto sus etiologías como los itinerarios terapeúticos aplicados incluyen a uywiris, a personas y animales del pasadopresente; y, también, a ritos cristianos católicos y protestantes. Estas prácticas muestran temporalidades que se yuxtaponen, pero también pueden operar de manera paralela.

\section{Referencias bibliográficas}

Andrade, S. (2004). Protestantismo indígena: procesos de conversión religiosa en la provincia de Chimborazo. Quito: Abya-Yala.

Andrade, S. (2010). Ethos evangélico, política indígena y medios de comunicación en el Ecuador. Revista Cultura y Religión, 4(1), 3-16. Recuperado de http://www.revistaculturayreligion.cl/index.php/culturayreligion/article/view/136

Carrasco, V. y Gavilán, V. (2009). Representaciones del cuerpo, sexo y género: una aproximación las diferencias sexuales entre los aymaras del norte de Chile. Chungara, 41(1), 83-100. Recuperado de http://dx.doi.org/10.4067/S0717$\underline{73562009000100006}$

Carrasco, A. M. y Gavilán, V. (2014). Género y etnicidad: ser hombre y ser mujer entre los aymara del altiplano chileno. Diálogo Andino, diciembre, (45), 169-180. Recuperado de https://dx.doi.org/10.4067/S0719-26812014000300014

Carrasco, A. M. y González, H. (2014). Movilidad poblacional y procesos de articulación rural-urbano entre los aymara del norte de Chile. Si Somos Americanos, 14(2), 217 231. Recuperado de http://dx.doi.org/10.4067/S0719-09482014000200009

Comaroff, J. L. y Comaroff, J. (2001). On personhood: An anthropological perspective from Africa. Social Identities, 7 (2), 267-283.

Cornejo Polar, A. (2003). Escribir en el aire. Ensayos sobre la heterogeneidad sociocultural de las literaturas andinas. Lima: Centro de Estudios Literarios Antonio Cornejo Polar.

Cuadro, I. (2008). Acercamiento antropológico del concepto de salud mental en los aymaras del sector Isluga. Revista Cultura y Religión, 2(3), 13-24.

De Arriaga, P. J. ([1920] 2002). La extirpación de la idolatría en el Perú. [Edición digital basada en la de Lima, Imprenta y Librería San Martí]. Alicante: Biblioteca Virtual Miguel de Cervantes. Recuperado de http://www.cervantesvirtual.com/FichaObra.html?Ref=5447

García, P. (2005). Aru pirwa. Diccionario aymara-castellano y castellano aymara. Iquique, Chile: Graficolor.

Gavilán, V. (2005). Identidades sociales a inicios del siglo XXI. Revista de Dialectología y Tradiciones Populares, 60(2), 77-102. Recuperado de http://rdtp.revistas.csic.es/index.php/rdtp/article/view/101/102 
Gavilán, V. (2013). De la administración de poblaciones y de etnicidades en los Andes del Sur: las dos caras de la colonización. Chungará, 45(4), 553-560. Recuperado de http://dx.doi.org/10.4067/S0717-73562013000400005

Gavilán, V. y Carrasco, A. M. (2009). Festividades y religiosidad andina en el norte chileno. Chungará, 41(1), 101-112. Recuperado de http://www.chungara.cl/Vols/2009/Vol41-1/Festividades_Andinas.pdf

Gavilán, V., Vigueras, P., Madariaga, C. y Parra, M. (2011). La sociedad y la cultura andina contemporánea: estudio de los saberes para la salud y la enfermedad en los pueblos originarios del norte de Chile. Revista de Indias, 71(252), 571-600. Recuperado de http://revistadeindias.revistas.csic.es/index.php/revistadeindias/article/view/872/944

Gavilán, V., Álvarez, I. y Cisternas, K. (2016). Los conceptos Pampa/Churu en la manufactura de las fajas confeccionadas por mujeres aymara del norte chileno. Chungará, 48(3), 429-440. Recuperado de https://dx.doi.org/10.4067/S071773562016005000024

Guerrero, B. (1990). Las campanas del dolor. Violencia y conflicto en los Andes chilenos. Iquique, Chile: Ediciones el Jote Errante.

Guerrero, B. (1994). A Dios rogando... Los pentecostales en la sociedad Aymara del norte grande de Chile. Amsterdam: Vrije Universiteit Press.

Guerrero, B. (1995). Medicina andina y medicina pentecostal en los aymaras del norte grande de Chile: del yatiri al pastor. Chungará, 27(2), 153-165.

Guevara, A. (2009). Entre el pastor evangélico y el dirigente indígena: discursos religiosos y políticos en dos "comunidades" Mapuche del sur de Chile. Revista Cultura y Religión, 3(2), 165-186. Recuperado de https://www.revistaculturayreligion.cl/index.php/culturayreligion/article/view/156

Grebe, M. E. (1984). Etnozoología andina: Concepciones e interacciones del hombre

andino con la fauna altiplánica. Estudios Atacameños [En línea], (7), 335-347. Recuperado de https://doi.org/10.22199/S07181043.1984.0007.00032

Gundermann, H. y González, H. (2008). Pautas de integración regional, migraciones, movilidad y redes sociales en los pueblos indígenas de Chile. Universum, 23(1), 82115. Recuperado de http://dx.doi.org/10.4067/S0718-23762008000100006

Kessel, J. (1992a). Holocausto al progreso. La Paz, Bolivia: Editorial Hisbol.

Kessel, J. (1992b). La organización tempo-espacial del trabajo entre los aymarás de Tarapacá: la perspectiva mitológica. Etnicidad, Economía y Simbolismo en los Andes. 11 Congreso Internacional de Etnohistoria. Coroico (pp. 267-298). La Paz: Hisbol.

Kessel, J. (1992c). Pachamama, La Virgina, la que creó el mundo y fundó el pueblo. Puno, Perú: CIDSA.

Mansilla, M. y Muñoz, W. (2017). ¿Evangélicos o aymaras?: dinámicas de las representaciones culturales de los evangélicos aymaras (Chile). Estudios Atacameños, (54), 239-258. Recuperado de https://revistas.ucn.cl/index.php/estudios-atacamenos/article/view/1720

Marcos, S. (1995). Pensamiento mesoamericno y categorías de género: un reto epistemológico. La palabra y el hombre, (95) (pp. 5-38). Veracruz: Universidad Veracruzana.

Martínez, G. (1976). El sistema de los uywiris en Isluga. Anales de la Universidad del Norte, (10), 255-327. Recuperado de 
https://scielo.conicyt.cl/scielo.php?script=sci_nlinks\&ref=2400287\&pid=S0718$1043200200230000500062 \& \operatorname{lng}=\mathrm{es}$

Price, R. (1983). First Time: The Historical Vision of an Afro-american People. Baltimore y Londres: The Johns Hopkins University Press.

Rappaport, J. (2002). La política de la memoria. Interpretación indígena de la historia en los Andes colombianos. Popayán: Editorial Universidad del Cauca.

Rivera, E. (2015). Conversión religiosa e identidad cultural en el altiplano peruano. Revista Cultura y Religión, IX(1), 51-63. Recuperado de http://revistaschilenas.uchile.cl/handle/2250/29406

Sánchez, R. (2015). Después de la muerte en el mundo andino. Una aproximación antropológica. Revista Cultura y Religión, IX(1), 64-81. Recuperado de https://www.revistaculturayreligion.cl/index.php/culturayreligion/article/view/591

Thompson, J. (1993). Ideología y cultura. México: Universidad Autónoma Metropolitana.

Tudela, P. (1992). Transformación religiosa y desintegración de la comunidad aymara tradicional en el norte de Chile. Bonn: Editorial Holos Verlag.

Urton, G. (2002). Codificación binaria en los khipus incaicos. Revista Andina, julio, (35), 938. Recuperado de http://www.revistaandinacbc.com/wpcontent/uploads/2016/ra35/ra-35-2002-01.pdf

Wright, P. (2015). Sueño, shamanismo y Evangelio en los Qom (Tobas) del Chaco argentino. Sociedad y Religión, XXV (4), 30-61. Recuperado de https://www.researchgate.net/publication/317533646_Sueno_shamanismo_y_Evang elio_en_los_Qom_Tobas_del_Chaco_argentin

\section{Cómo citar este artículo}

Gavilán, V. y Vigueras, P. (2020). Temporalidades y memorias corporizadas en los rituales aymaras del norte de Chile. Revista Cultura \& Religión, 14(2), 100-120. 